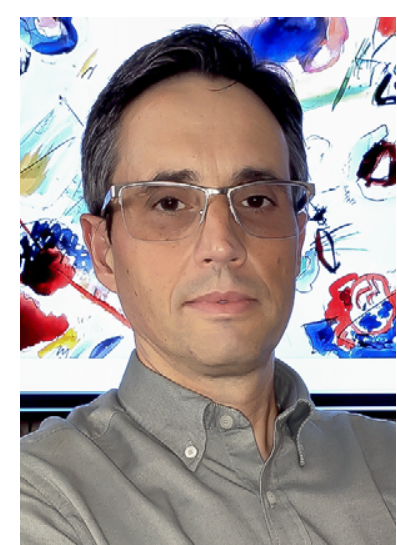

Achatar a curva (epidemiológica). Álcool gel. Boletim epidemiológico da Direção Geral de Saúde (DGS). Cadeia de contágio. Casos confirmados/ recuperados/suspeitos. Cerca sanitária. Confinamento. Coronavírus. COVID-19. Cuidados intensivos. Desconfinamento. Dexametasona. Distanciamento social. Dois metros. Ensino à distância. Escolas fechadas. Espaços públicos. EPI (luvas, máscaras, viseiras,...). Epidemia. Estado de alerta/contingência/ calamidade/emergência. Etiqueta respiratória. Fase de contenção/mitigação/supressão. Fique em casa. Gotículas. Grupos de risco. Hidroxicloroquina. Higiene das mãos/superfícies. Imunidade comunitária/de grupo. Isolamento profilático (quarentena). Óbitos. Organização Mundial de Saúde (OMS). Pandemia. Plano de contingência. Portador assintomático. Quartos de pressão negativa. Remdesivir. SARS-CoV-2. Sintomas (febre, tosse, dificuldade respiratória,...). Taxa (de letalidade, de transmissão, $R_{0}, R_{\mathrm{t}}$ ). Teletrabalho. Testes serológicos. Transmissão comunitária. Vacina. Ventilador. Vigilância ativa e passiva. Wuhan. Zaragatoa.

A história do tempo que vivemos não pode ser escrita sem muitos dos termos anteriores. São palavras e expressões ditas e escritas nos últimos meses e que servem como prova do tempo que passa. Faltarão outras que o tempo se encarregará por (re)escrever. Há, pelo menos uma, que deveria ter maior visibilidade nestes tempos. Passeia-se entre nós, toca-nos, por vezes não a sentimos, mas está omnipresente: Química. Quase não se dá por ela, mas participa na chamada linha da frente do combate à COVID-19. Materiais dos EPI, instrumentação médica, produtos de lavagem e desinfeção das mãos e superfícies, ou como pilar na busca de tratamento e vacinas (pede-se magia na retorta de alquimista...). Também está presente nos momentos emotivos, tão férteis neste tempo de pandemia, em que uma série de neurotransmissores cumprem o seu papel. Temos o desassossego do confinamento, os humores dos profissionais de muitas áreas que arduamente contribuem para ultrapassar este período, a dor que desatina sem doer, a alegria de quem vence a doença, o pesar por aqueles que partem...

Dado o papel da química no contexto da COVID-19, o QUímICA não poderia deixar de abordar o tema neste número. Nesta pequena viagem poderá constatar que existem muitos pontos de contacto entre a cinética química e a dinâmica epidemiológica. Reconhecerá também o papel dos agentes desinfetantes, nomeadamente sabões e produtos à base de álcool, e a plasticidade dos polímeros na luta contra o SARS-CoV-2. Mas o mundo pula e avança e nem tudo tem de ser COVID-19. Espaço ainda para a importância das micro-ondas em síntese química, aqui na perspetiva dos MOFs, a utilização de biossorventes para a remoção de elementos potencialmente tóxicos em águas residuais contaminadas e a homenagem à química no feminino, na figura de uma mulher de fibra, Stephanie Louise Kwolek. Uma chamada de atenção também para os sentimentos xenófobos, sexistas, racistas e outras discriminações que, infelizmente, fazem parte do nosso quotidiano. Neste contexto, fique a par da decisão da SPQ de subscrever o manifesto de inclusão e diversidade da Royal Society of Chemistry. Apetece revisitar aqui a "Lágrima de Preta" de António Gedeão...

Um apontamento final neste que é o primeiro número do QUímICA de 2020. 0 virar de um ano significa, por vezes, um recomeço. Recomeçar. Uma palavra que poderia também figurar no primeiro parágrafo deste editorial. Recomeça... / Se puderes / Sem angústia / E sem pressa. / E os passos que deres, / Nesse caminho duro / Do futuro / Dá-os em liberdade. / Enquanto não alcances / Não descanses. / De nenhum fruto queiras só metade... (excerto de "Sísifo", Miguel Torga).

\section{Paulo Mendes}

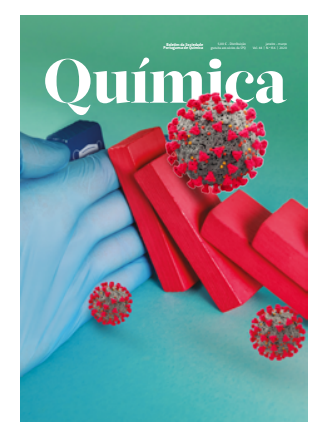

BOLETIM DA SOCIEDADE PORTUGUESA DE QUÍMICA PROPRIEDADE DE SOCIEDADE PORTUGUESA DE QUÍMICA

NIPC: 501139265

ISSN $0870-1180$

Registo na ERC n. ${ }^{\circ} 125525$

Depósito Legal n. ${ }^{\circ} 51420 / 91$

Publicação Trimestral

N. ${ }^{156}$, janeiro-março 2020

\section{REDAÇÃO E ADMINISTRAÇÃO}

Av. da República, 45 - 3. ${ }^{\circ}$ Esq. - 1050-187 Lisboa Tel.: 217934637 • Fax: 217952349

bspq@uevora.pt·www.spq.pt

Diretor: Paulo Mendes

Diretores-adjuntos: Ana Paula Esteves, Bruno Machado, Maria José Lourenço, Marta Piñeiro Gómez, Vasco D.B. Bonifácio

Comissão de Aconselhamento Editorial:

Augusto Tomé, Helder T. Gomes, João Paulo R. F. André, Joaquim L. Faria, Jorge Morgado, Mário N. Berberan-Santos

\section{ESTATUTO EDITORIAL}

Disponível em:

www.spq.pt/boletim/estatuto_editorial

\section{PUBLICIDADE}

Sociedade Portuguesa de Química

secretariado@spq.pt

\section{DESIGN GRÁFICO E PAGINAÇ̃̃o}

Rodrigo Nina

www.rodrigonina.com

rodrigo.pnina@gmail.com

Tel.: 964819822

\section{IMPRESSÃO E ACABAMENTO}

Tipografia Lessa

Pta dos Mogos, 157 - Z. Ind. de Vermoim

4470-343 Maia

+351229441603

geral@tipografialessa.pt

Tiragem: 1.500 exemplares

As colaborações assinadas são da exclusiva responsabilidade dos seus autores, não vinculando de forma alguma a SPQ, nem a Direção do QUíMICA. São autorizadas e estimuladas todas as citações e transcrições, desde que seja indicada a fonte, sem prejuízo da necessária autorização por parte do(s) autor(es) quando se trate de colaborações assinadas. As normas de colaboração e as instruções para os autores podem ser encontradas no sítio web da SPQ.

PUBLICAÇÃO SUBSIDIADA PELA EC

Apoio do Programa Operacional Ciência, Tecnologia, Inovação do Quadro Comunitário de Apoio III 